\title{
THE MEASUREMENT OF GROUND MOTION OF DESTRUCTIVE EARTHQUAKES
}

\author{
By D. E. Hudson
}

\begin{abstract}
The need for a greatly expanded network of strong-motion accelerographs throughout the seismic regions of the world is stressed. A summary of the characteristics of currently available strong-motion accelerographs is presented, and the design details are given for an instrument suitable for acquiring the basic data needed by structural engineers for earthquake resistant design. It is shown that for such an instrument, the natural period must be less than 0.1 seconds, and that the recording speed must be at least $1 \mathrm{~cm} / \mathrm{sec}$. The critical nature of the inertia starting device is discussed, and some information is given on the transient response of the standard pendulum starter used in the United States Coast and Geodetic Survey Strong-Motion Accelerograph. The use of simpler, non-time-recording instruments such as the U.S.C.G.S. Seismoscope to supplement the accelerograph network is described.
\end{abstract}

\section{INTRODUCTION}

The occurrence of a great earthquake is a powerful stimulus to engineering researches in earthquake-resistant design, and structural engineers should always be prepared to make use of the general interest aroused by destructive earthquakes to further their studies in this field. At such times it is wise to evaluate anew the adequacy of our past knowledge, and to initiate new programs to supply deficiencies in it.

The Chilean earthquakes of May 1960, with a main shock of magnitude 8.5, form one of the largest series of destructive earthquakes of history. Coming just before the Second World Conference on Earthquake Engineering in Tokyo and Kyoto, Japan, at a time when the attention of a large number of earthquake engineers and seismologists was foccussed on such problems, the Chilean earthquakes offered an unparalleled opportunity for field studies of destructive earthquakes.

The importance of field studies of undamaged as well as damaged structures cannot be overemphasized. It must be realized, however, that such studies must always be incomplete without an accurate knowledge of the actual ground motions at each particular site. In this respect we must regretfully report that we do not have available from the Chilean earthquakes a single measurement of ground motion at any point at which significant damage occurred.

This situation is unfortunately far from uncommon. In spite of the fact that instrumental seismology has now been in existence for nearly 100 years, we do not as yet have a single ground acceleration record from the central region of a truly major earthquake. The largest ground acceleration record obtained by a U. S. Coast and Geodetic Survey Strong-Motion Accelerograph was from the El Centro earthquake of May 18, 1940, recorded at a point about 30 miles from the center of a magnitude 7 earthquake. The only accurate ground acceleration data available on potentially destructive ground motion anywhere in the world is that from the dozen or so earthquakes which have been recorded by the U. S. Coast and Geodetic Survey Network in California and the Pacific Coast States, and all studies of the dynamic response of structures to earthquakes have been based on this meager data. 
The present lack of adequate strong motion accelerograph coverage cannot be attributed to a lack of knowledge as to how to proceed, nor to an absence of warnings as to the difficulties that would face earthquake engineers in the absence of such data. As early as the 1920's Dr. K. Suyehiro, the first director of the Earthquake Research Institute of the University of Tokyo, outlined clearly the type of accelerographs that would be needed, and emphasized again and again the importance of instruments specially designed to record the data required by structural engineers. During his American lectures on Engineering Seismology in 1931, he said: "Engineering Seismologists must prepare suitable strong-motion siesmometers and accelerographs, and after distributing them in the seismic regions await with patience the useful data that must come in the future. . . The amplitude and the period of the main principal motions taken from a seismogram have generally not much significance for the engineer. The requisite data for him are the acceleration and its period as recorded directly by an accelerograph suitable for engineering use." ${ }^{*} *$

These ideas of Dr. Suyehiro were followed up in the United States by Mr. J. R. Freeman, who emphasized strongly in his important book Earthquake Damage and Earthquake Insurance the need for ground acceleration measurements. These efforts culminated in 1931 in an allocation from the U. S. Congress to the U. S. Coast and Geodetic Survey for the development of suitable accelerographs. The first strongmotion earthquake recordings were obtained during the Long Beach earthquake of March 10, 1933, of magnitude 6.3, and since that time useful ground acceleration records have been obtained for about 20 moderately strong earthquakes occurring in the California-Pacific Coast region. There are at present about 60 of the standard U. S. Coast and Geodetic Survey Strong-Motion Accelerographs in operation in the Western United States, and a few of these instruments have been sent to other countries to serve as prototypes for new networks.

A similar network of strong-motion accelerographs is now installed in Japan, and comparably useful records may be expected from that region. Two accelerometers suitable for the purpose were developed by the Japanese "Strong Motion Acceleration Committee" (S.M.A.C.) formed in $1951 .^{3}$ As of 1960 , approximately 50 SMAC Type Accelerographs and 15 DC Type Accelerographs were in operation in Japan. ${ }^{4}$

\section{The Destgn of a Strong-Motion Accelerometer}

In order to understand the basic design requirements of a seismograph suitable for engineering applications, we must first consider the use to which the data are to be put, and second, the characteristics of the ground motions that are to be measured.

The fundamental problem which confronts the structural engineer in earthquake-resistant design is the determination of the dynamic strains induced in structures by the base motion. The equations relating the earthquake ground motion to the resulting structural strains give the relative displacements of the structure in terms of the ground acceleration. It thus develops that, for the desired calculation of structural responses, the true acceleration of the ground as a function of time is required.

\footnotetext{
* Numbers refer to references at the end of the paper.
} 
There is, of course, a simple theoretical relationship between ground displacement, velocity, and acceleration, so that it might be thought that it is immaterial which of these quantities is originally measured. Considering the accuracy needed, however, it turns out that it is essential that the original measurement be of ground acceleration. This is a consequence of the fact that integration is inherently a more accurate process than differentiation. An acceleration-time curve can be integrated to give velocity and again to give displacement with an acceptable accuracy. It would not in general be possible to reverse this process and obtain a usable acceleration-time curve from a displacement curve by differentiation. The inevitable

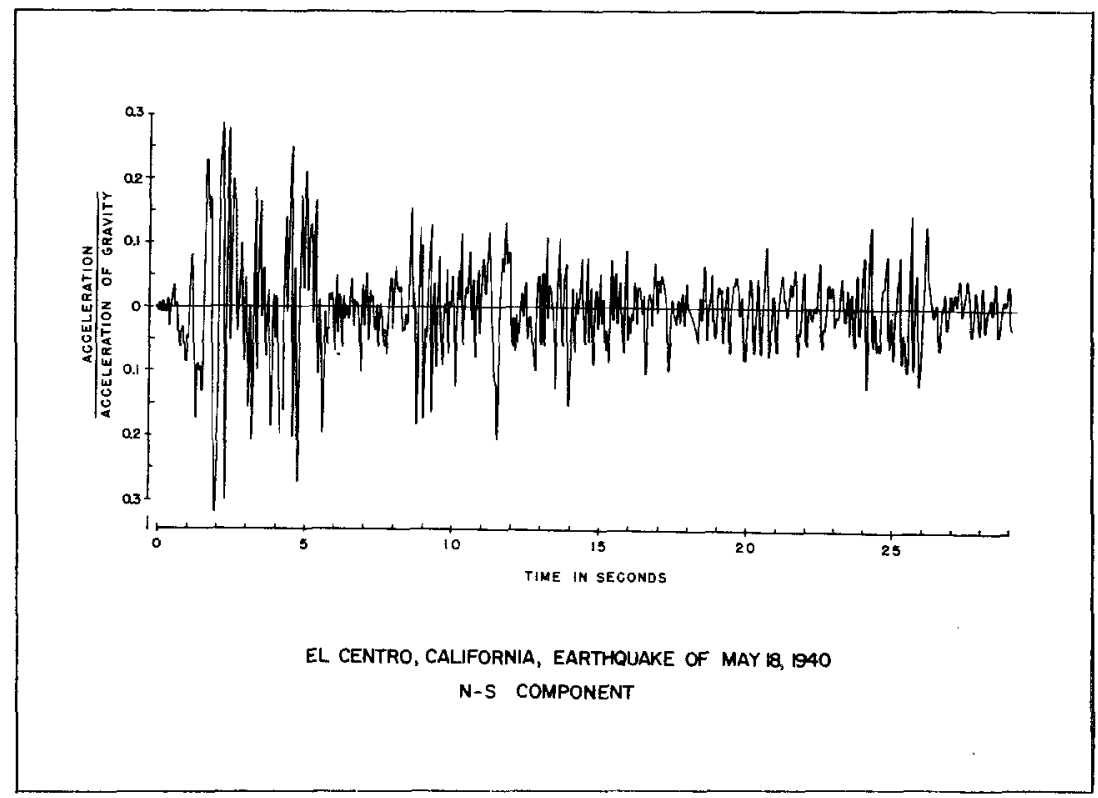

FIG. 1. Typical ground acceleration-time record for a strong-motion earthquake.

loss of accuracy in differentiation cannot be avoided, no matter how the operation is carried out, be it by electrical, mechanical, or numerical techniques. The first important conclusion, therefore, is that the basic transducer in the seismograph should operate as an accelerometer for the range of periods to be included in the measurement.

The natural period which the instrument should have to ensure that it behaves as an accelerometer will depend upon the shortest periods appearing in the ground acceleration-time records. An idea of the magnitude of these shortest periods may be obtained from the response-spectrum curves calculated for California earthquakes.

It should be noted that in basing an instrumental design on measurements of earthquakes in the Western United States, we are supposing that earthquakes in other parts of the world will have similar characteristics. This may not be true, although there do not seem to be any geologic reasons why the major earthquakes in various parts of the world should have markedly different characteristics as far 
as periods and magnitudes of the ground motions are concerned. It is, of course, much to be desired that accurate ground-acceleration records be obtained from other seismic regions so that more definite information on this point will be available. This is particularly desirable for areas that have unusual characteristics of local geology.

In figure 1 is shown a typical ground acceleration record as obtained in California on the standard U. S. Coast and Geodetic Survey Strong-Motion Accelerograph $^{5}$. In figure 2 is shown the velocity response spectrum corresponding to the

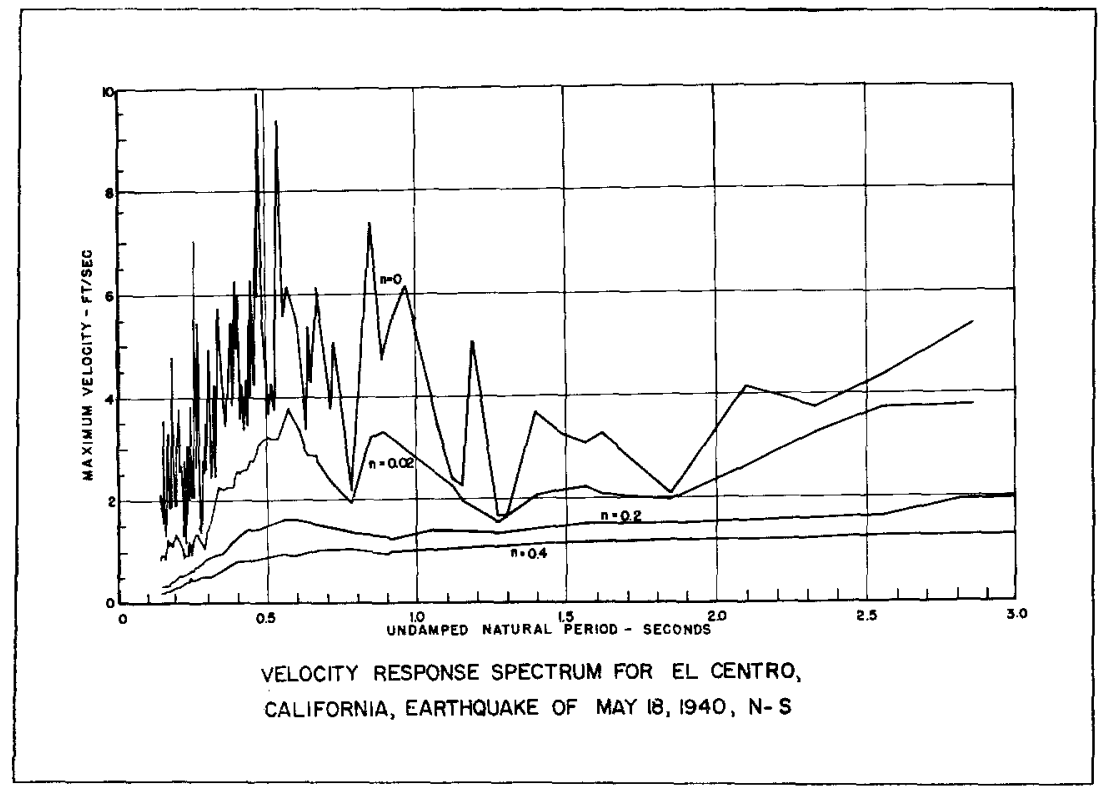

FIG. 2. Maximum relative velocity response spectrum for the earthquake of figure 1.

acceleration-time curve of figure $1^{6}$. This response spectrum gives directly the maximum relative velocity of a single-degree-of-freedom spring-mass-dashpot system acted upon by the prescribed base acceleration of figure 1. The zero-damped response curve will have the same general configuration as the Fourier spectrum of the acceleration-time curve, and hence indicates directly the period components of the exciting motion.

A study of a number of response-spectrum curves of the type shown in figure 2 shows that significant responses occur down to periods of about 0.1 seconds in California earthquakes. It therefore follows that the basic transducer element should have a natural period of somewhat less than 0.1 seconds, along with damping of the order of $50-70 \%$ of critical, to serve as an accelerometer for all important ground periods.

\section{ACCELerometer Sensitivity}

The instrument sensitivity must be a compromise between the desire to obtain a reasonable accuracy for small earthquakes, and the danger that a large earthquake might give an off-scale deflection. The largest peak acceleration so far recorded by 
the U.S. Coast and Geodetic Survey Accelerographs is $0.3 \mathrm{~g}$, at a distance of about 30 miles from a magnitude 7 earthquake. The California accelerographs have been adjusted to give a full-scale reading of about $0.5 \mathrm{~g}$. This value might well be exceeded in the epicentral area of a major earthquake, and there is thus a real possibility of the loss of significant information under present conditions. Some of the early models of the U.S. Coast and Geodetic Survey Accelerographs were equipped with a double optical system so that records at two different magnifications could be simultaneously recorded 7 . This would seem to be useful feature to incorporate in the instrument.

\section{Recording Speeds and Technique}

Considering the accuracy needed for making the required analysis of structural response from the accelerograph record, a recording speed of at least $1 \mathrm{~cm} / \mathrm{sec}$ is necessary. This is a sufficiently high speed so that continuous recording is impracticable, and thus a starting device actuated by the earthquake itself is required. The recording system should be arranged so that after starting, a record length of two-to-three minutes would be obtained, after which the mechanism would shut down automatically and reset itself to repeat the sequence of events. It is desirable to have a sufficient supply of recording material so that a number of earthquakes can be recorded without servicing the instrument.

Various types of recording methods have been used for strong-motion accelerographs. Photographic recording, waxed paper and stylus systems, and smoked paper drums have all been successfully employed.

\section{The Starting Device}

As mentioned above, the recording speed required is sufficiently high so that it is not feasible to use continuous recording, and hence some type of inertial switch operated by the earthquake itself is necessary. This starting device is perhaps the most critical component of the whole accelerograph, and is the part most difficult to specify and design. For this reason, some details of the pendulum starter used in the U.S. Coast and Geodetic Survey Strong-Motion Accelerograph will be given.

The starting device poses some difficult timing problems. Since the very beginning of the ground acceleration record may contain significant acceleration peaks, it is essential that the device be triggered as soon as possible, and that the delay times in the starter, the relay system, and the motor drive be as small as possible. On the other hand, if the starter operates at values of acceleration-time excitation that are too low, it may be set off by extraneous non-seismic vibrations or by a series of small earthquakes, with the danger that the recording paper supply may be exhausted before a strong earthquake occurs.

The horizontal pendulum starter developed by the U. S. Coast and Geodetic Survey and used successfully by them for the past 25 years is shown in the diagram of figure $3^{7,8}$. The pendulum has a natural period of one second, and the damping is approximately 30 per cent of critical damping. A displacement of the electrical contacts of $0.05 \mathrm{~cm}$ in any horizontal direction is sufficient to close the platinum contacts and start the recording cycle. It was found that more reliable operation of the starter system was obtained with a break-circuit type of operation, using a 


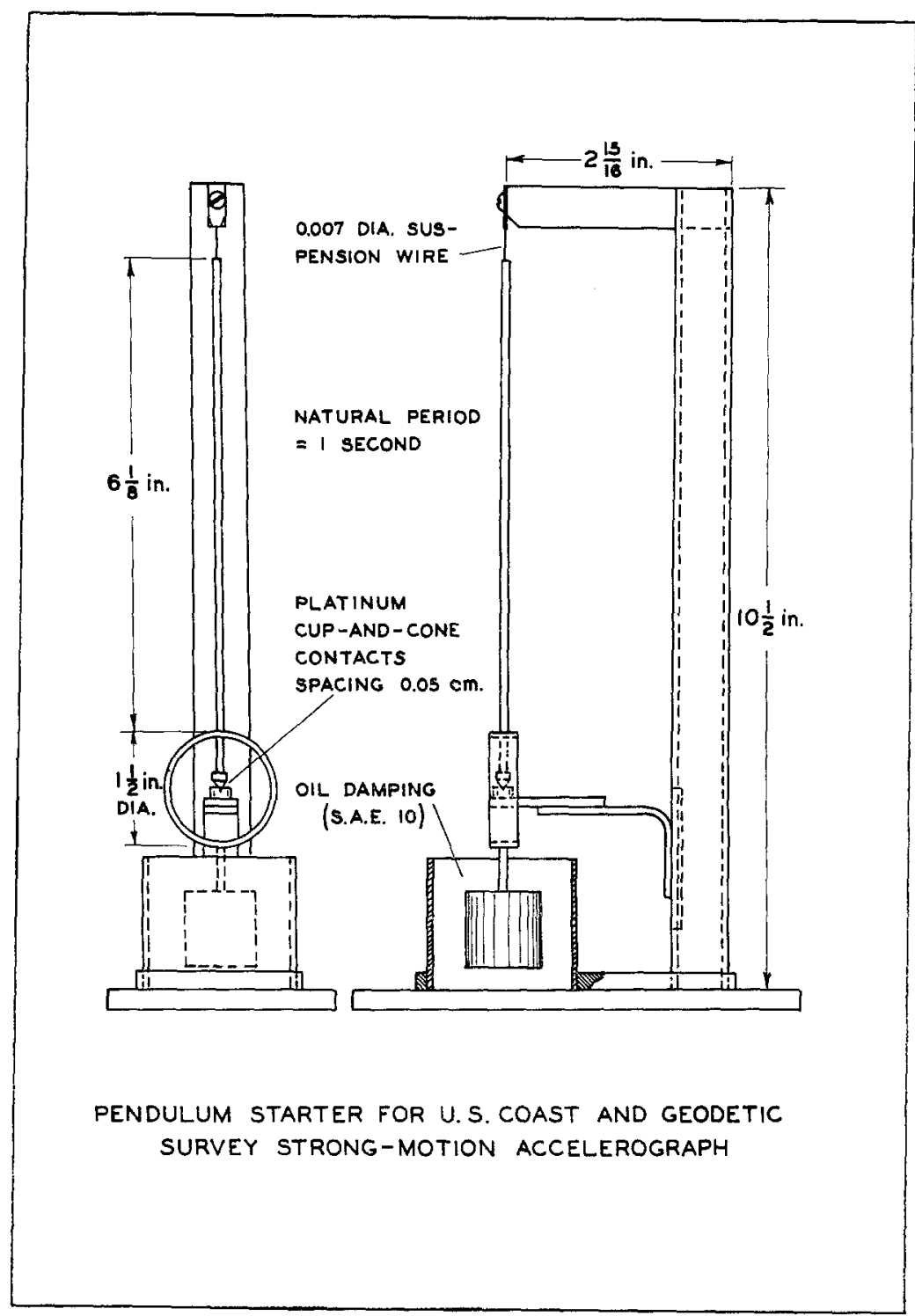

FIG. 3. Main features and dimensions of the U.S. Coast and Geodetic Survey pendulum starter for Strong-Motion Accelerograph.

holding relay. In figure 4 is shown a schematic diagram of the starter relay and control system as currently used by the U. S. Coast and Geodetic Survey.

The time required to start the recording process with the above system is of the order of 0.2 seconds. Any starting device will of course have its own dynamic characteristics, and various combinations of acceleration magnitude, time duration, and wave shape may cause sufficient relative motions to initiate operation. The optimum combination of characteristics for a given area will need to be determined by experience. 


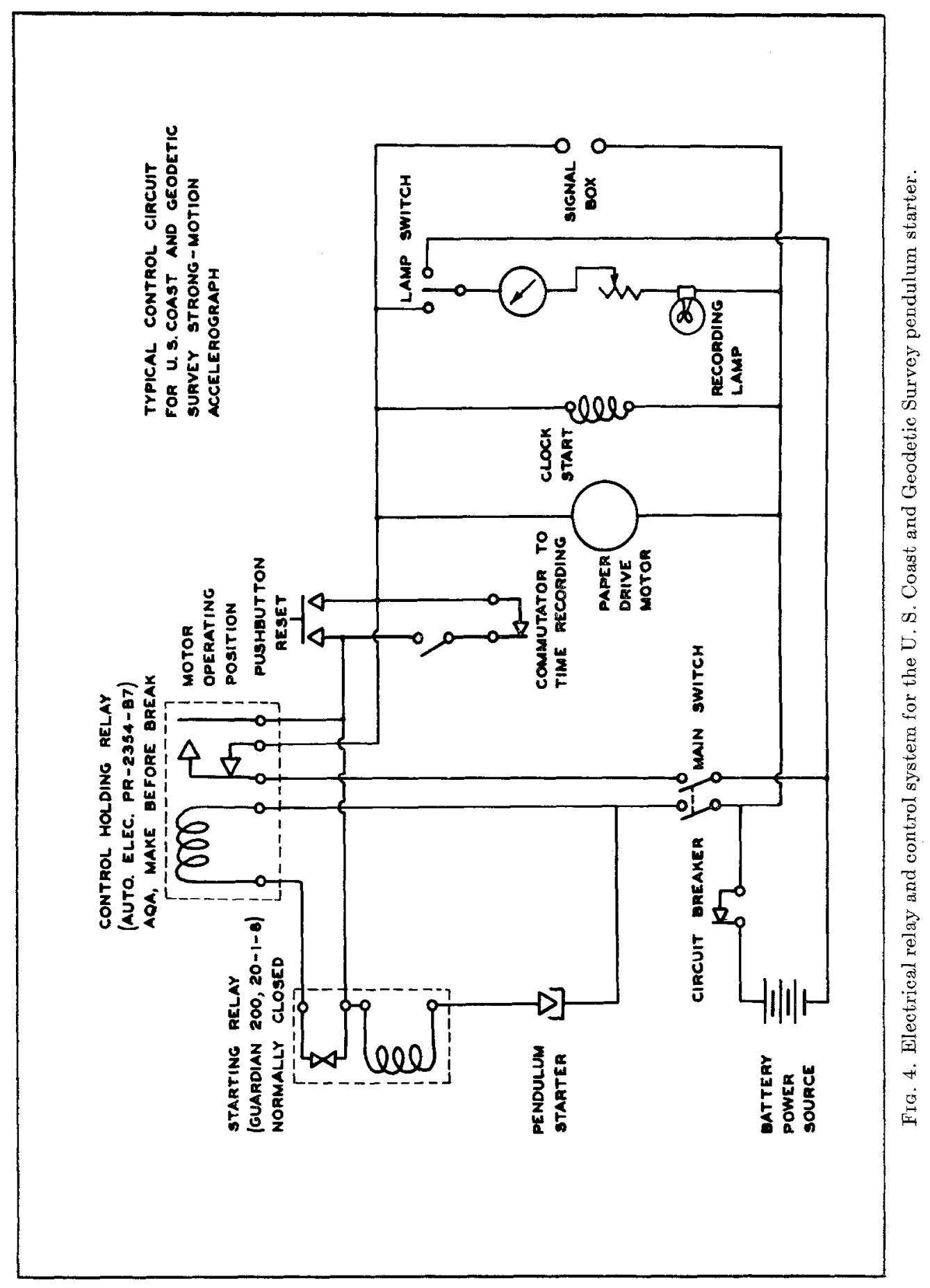


The only dynamic-response information on the U. S. Coast and Geodetic Survey pendulum which has been hitherto published are curves giving the steady-state response to a sinusoidal base acceleration ${ }^{9}$. The operating conditions of interest are, however, transient conditions, and a more elaborate analysis is required in order to establish the transient dynamic characteristics of the device. In figure 5 are given curves which show the time required to close the pendulum contacts as

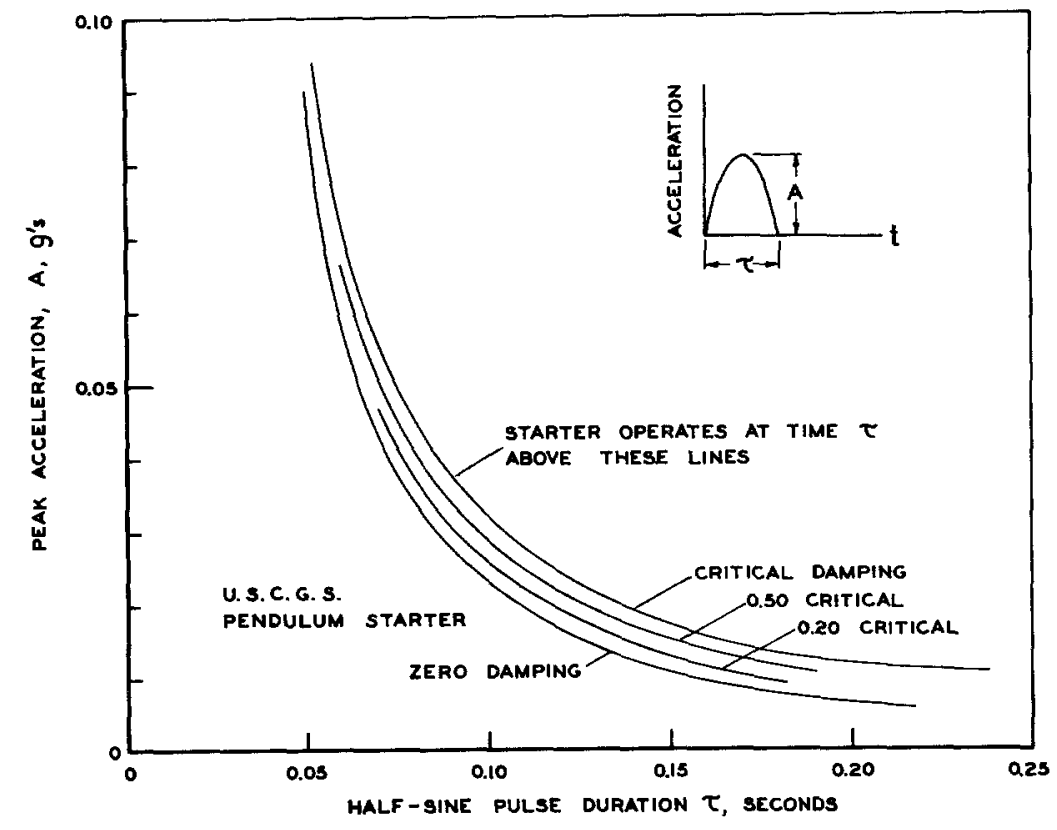

Fig. 5. Transient response curves for the U.S. Coast and Geodetic Survey pendulum starter.

a function of peak acceleration and time duration, supposing that the starter operates after one half-sine pulse of acceleration starting from rest. Another way of looking at this particular excitation is to say that if a constant sine-wave train of given amplitude and frequency starts at time $t=0$ with the starter at rest, the curves will show the combination of peak acceleration amplitude and sine-wave frequency that will insure starter operation within the first one-half cycle of acceleration. These curves have been calculated for the particular characteristics given above for the U. S. Coast and Geodetic Survey starter. This particular halfsine acceleration pulse is of course only a very approximate model for the actual state of affairs, since the operation of the starter would likely be preceded by a gradually increasing series of plus and minus acceleration peaks. The curves of figure 5 should be of assistance in evaluating the orders of magnitude involved in the starter delay times under true transient conditions. 
It will be observed from the curves of figure 5 that the pendulum damping is not a critical parameter. The steady-state curves of ref. 9 are for critical pendulum damping, although the starter as used in the field with a light S.A.E. 10 oil in the damper cup actually has a damping of from 20 to $40 \%$ of critical. The curves of figure 5 show, however, that differences in damping of this order will not be of significance for the operation of the device.

A considerable amount of experimental work has been carried out by the U. S. Coast and Geodetic Survey to develop a starter activated by vertical accelerations. Difficulties were encountered with the long-time stability of the pendulum system, however, which led the U. S. Coast and Geodetic Survey to prefer the horizontal system.

It is a fortunate thing that most of the earthquakes so far recorded on the U.S. Coast and Geodetic Strong-Motion Accelerograph have had maximum acceleration peaks occurring several cycles after the initial peaks which triggered the instrument, so that little data of significance has been lost because of starting delays.

As mentioned above, the starter is perhaps the most critical element of an accelerometer system for engineering applications. It is probable that increased research and development would lead to desirable improvements in characteristics and reliability.

\section{Currently Available Accelerographs}

As a means of comparing several strong-motion accelerographs designed along the above lines which are currently in use, a table of basic characteristics has been prepared. The U. S. Coast and Geodetic Survey Strong-Motion Accelerograph shown in figure 6 contains two horizontal 5 -second pendulums as well as the accelerometer transducers. These 5-second transducers will act as displacement instruments for waves of period shorter than about 3 seconds. All of these instruments include self-contained power supplies so that their operation is independent of power-line failures, which are a likely consequence of destructive earthquakes. The two Japanese instruments of figures 7 and 8 are commercially available as indicated in the table. Arrangements for construction of the standard U. S. Coast and Geodetic Survey instrument of figure 6 can be made through the U. S. Coast and Geodetic Survey.

\section{A Strong-Motion Accelerograph Network}

Considering the fact that it is very desirable to obtain ground acceleration data within 10-20 miles of the epicenter of earthquakes, it is clear that a large number of accelerographs will be required, compared with the numbers of teleseismic seismographs that are needed. Such strong-motion stations should be distributed throughout seismic regions with a spacing of not greater than 100 miles, with an increased number of instruments in the vicinity of cities and important engineering structures such as dams and nuclear power plants.

At present, 7 U. S. Coast and Geodetic Survey Accelerographs are located in the upper stories of tall buildings. From simultaneous measurements of the ground acceleration and the acceleration response of the structure, important structural dynamic properties of the building can be determined ${ }^{10}$.

The chief difficulties in the establishment of suitable accelerograph networks 
are the high cost of the instruments, and the requirement of a permanent servicing organization. The cost of any of the existing accelerographs is in the range of $\$ 3000$ $\$ 5000$ depending on the number of units acquired. The complexity of the apparatus and the requirement of some battery-operated components make it necessary to set up a periodic servicing and checking system. To insure proper operation of the instruments, a trained technician should check the accelerograph at least once each month.

Characteristics of Strong-Motion Earthquake Accelerographs

\begin{tabular}{|c|c|c|c|}
\hline & U.S.C. and G.S. (fig. 6) & SMAC (fig. 7) & D.C.-3 (fig. 8) \\
\hline Natural Period, sec & $\begin{array}{lll}0.045 & 0.0668 & 0.0848\end{array}$ & 0.10 & 0.10 \\
\hline Sensitivity, mm/0.1g & $\begin{array}{lll}6.4 & 13.0 & 19.4\end{array}$ & 4.0 & 4.0 \\
\hline Damping & 0.60 Critical & Critical & Critical \\
\hline Damping Mechanism & Magnetic & Air Piston & Oil Piston \\
\hline Recording Range & $0.01-1.0 \mathrm{~g}$ & $0.01-1.0 \mathrm{~g}$ & $0.01-1.0 \mathrm{~g}$ \\
\hline $\begin{array}{l}\text { Recording Speed, mm/ } \\
\text { sec }\end{array}$ & 10 & 10 & 10 \\
\hline Recording Medium & Photographic Paper & Waxed Paper & Smoked Paper \\
\hline Recording Drive & Electric Motor & $\begin{array}{l}\text { Hand-wound } \\
\text { Mech. Spring } \\
\text { Motor }\end{array}$ & Electric Motor \\
\hline Recording Time Duration & $11 / 4 \min$ & $3 \min$ & $3 \min$ \\
\hline No. Repeat Cycles & 5 & 5 & 3 \\
\hline Components & 2 Horiz., 1 Vert. & 2 Horiz., 1 Vert. & 2 Horiz., 1 Vert. \\
\hline Starter Type & $\begin{array}{l}\text { Horiz. Pend. Elect. } \\
\text { Contact }\end{array}$ & $\begin{array}{l}\text { Vert. Pend. Elect. } \\
\text { Con. }\end{array}$ & $\begin{array}{l}\text { Vert. Pend. Elect. } \\
\text { Con. }\end{array}$ \\
\hline Starter Period, sec & 1. Sec., 0.3 Crit. Damp. & $0.3 \mathrm{Sec}$ & 0.3 Sec. \\
\hline Starter Sensitivity & $\begin{array}{l}0.05 \mathrm{~cm} \text { Displacement } \\
\text { of Center of Osc. }\end{array}$ & $0.01 \mathrm{~g}$ & $0.01 \mathrm{~g}$ \\
\hline Auxiliary Starter & - & Mechanical, $0.10 \mathrm{~g}$ & - \\
\hline Time Marking & $1 / 2 \mathrm{Sec}$ & $1 \mathrm{Sec}$ & $1 / 5,1 / 2$ or $1 \mathrm{Sec}$ \\
\hline Power Supply & $\begin{array}{r}\text { Wet Storage Batteries } \\
\text { Power Line Charging }\end{array}$ & 4 Dry Cells & 3 Dry Cells \\
\hline Size, Overall, cm & $\begin{array}{l}32 \times 50 \times 115 \text { Without } \\
\text { Batteries }\end{array}$ & $37 \times 54 \times 54$ & $40 \times 60 \times 80$ \\
\hline Total Weight, kg & 50 Without Batteries & 100 & 200 \\
\hline Supplier & $\begin{array}{l}\text { U.S.C. and G.S. (Not } \\
\text { Commercially Avail- } \\
\text { able) }\end{array}$ & $\begin{array}{l}\text { Akashi Seisakusho } \\
\text { Co. }\end{array}$ & $\begin{array}{l}\text { Hosaka Seismo- } \\
\text { graph Co. }\end{array}$ \\
\hline
\end{tabular}

\section{A New Type of Strong-Motion Earthquake Recorder}

Because of the cost and complexity of a recording accelerograph of the type described above, there have been many attempts to produce a simplified device which would give some of the essential features of the ground motion. During the past three years a new simplified instrument has been developed by a cooperative effort involving the U.S. Coast and Geodetic Survey, the California Institute of Technology, the Earthquake Engineering Research Institute, and the National Science Foundation ${ }^{11}$. 


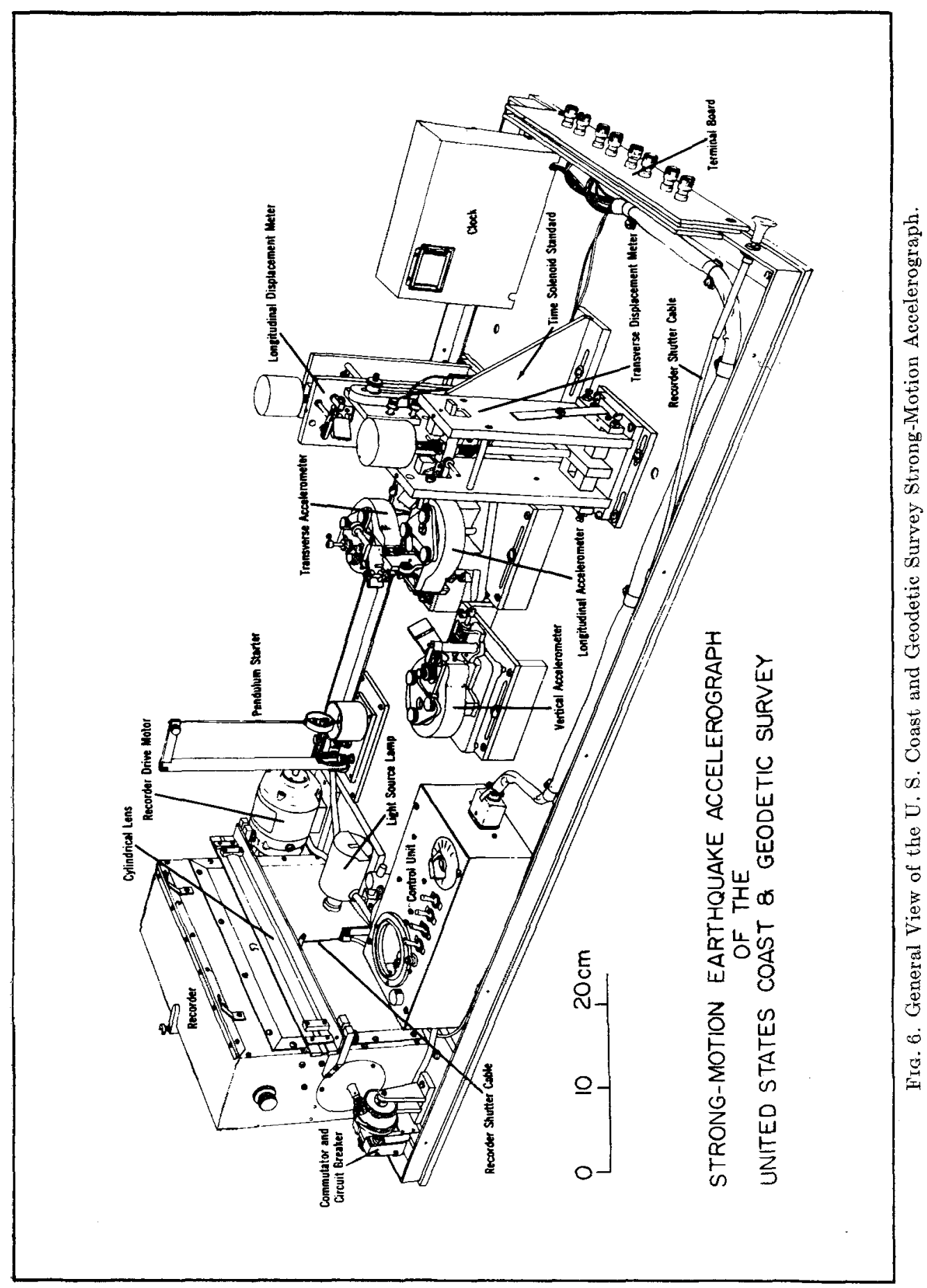




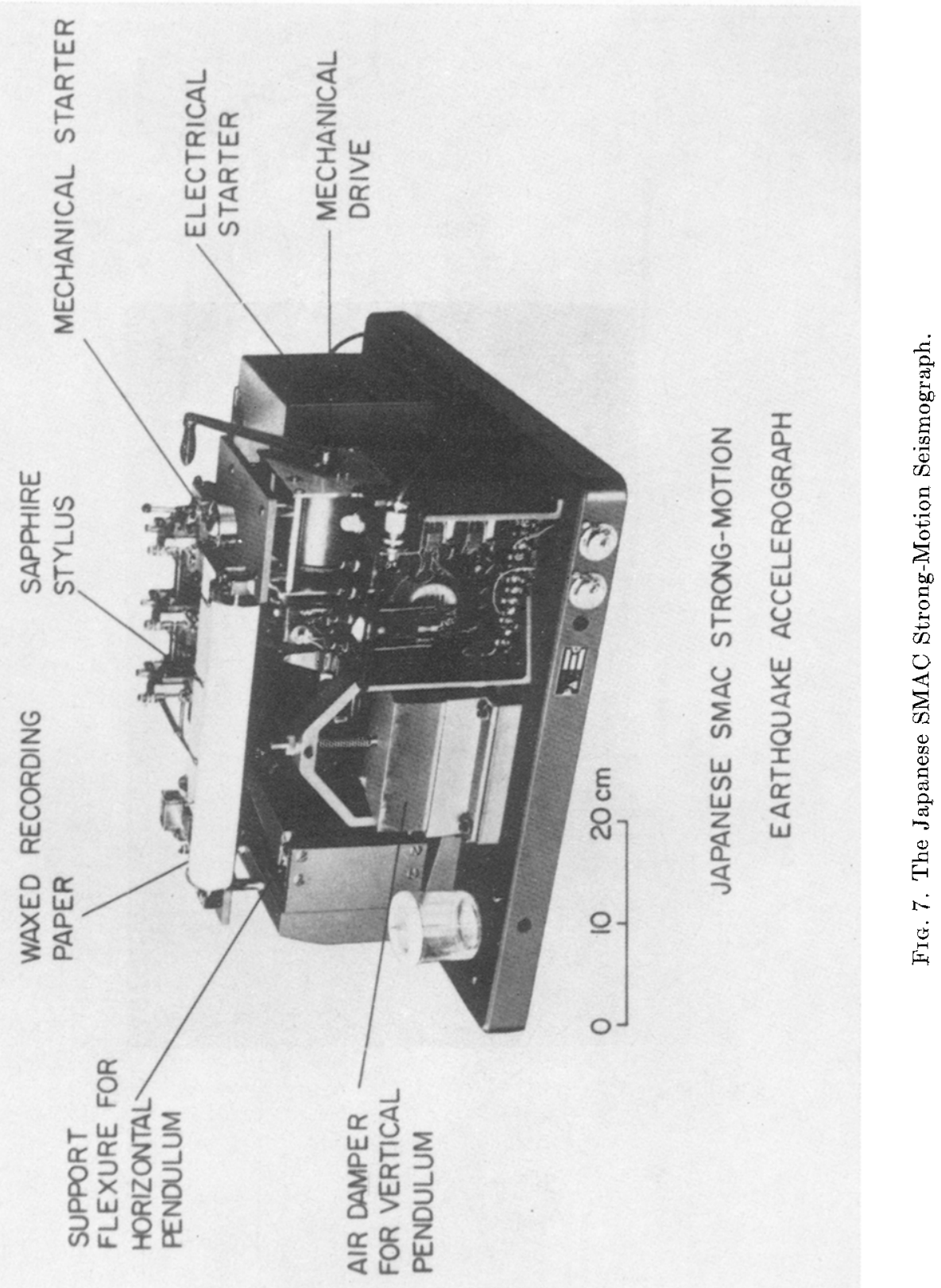




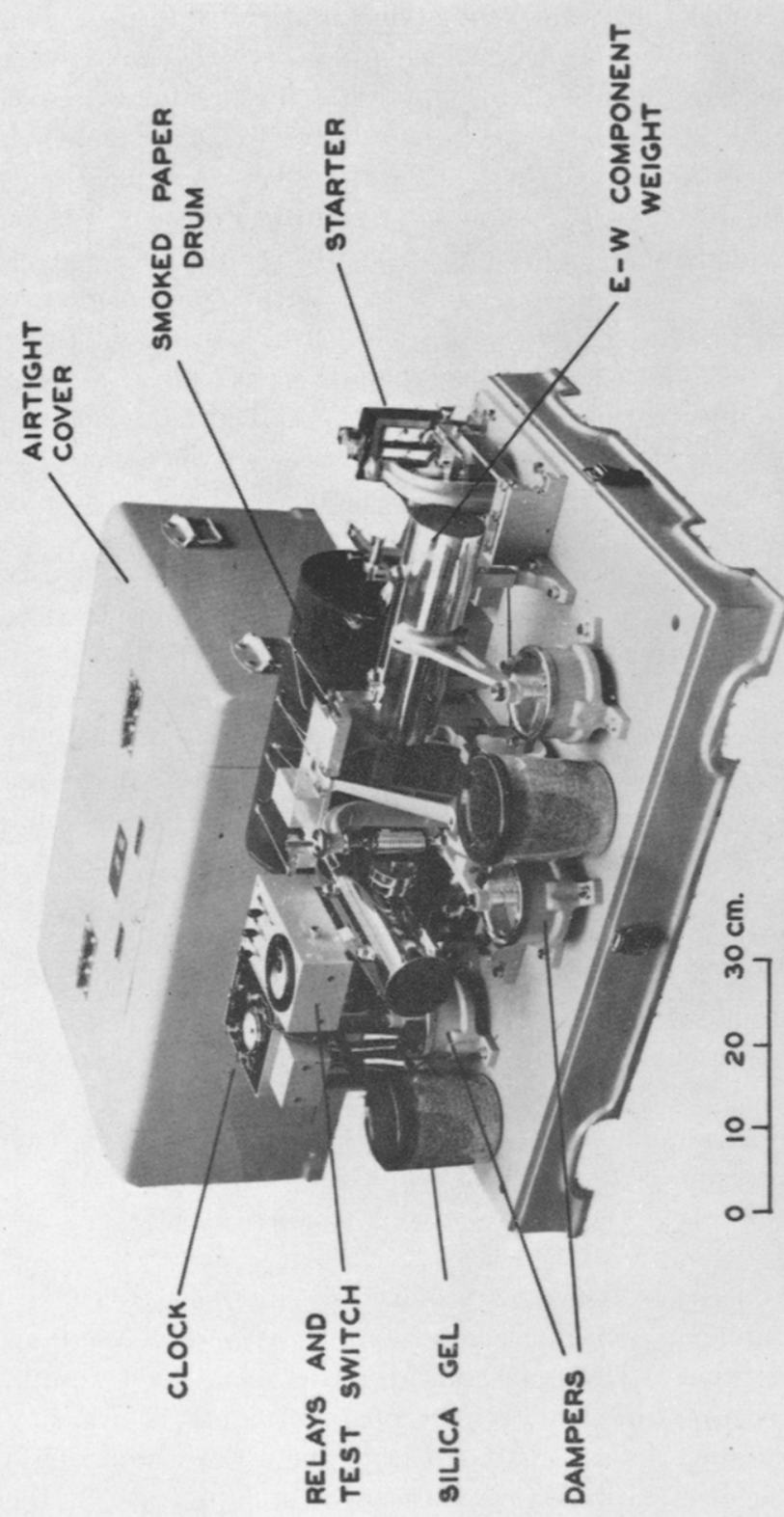

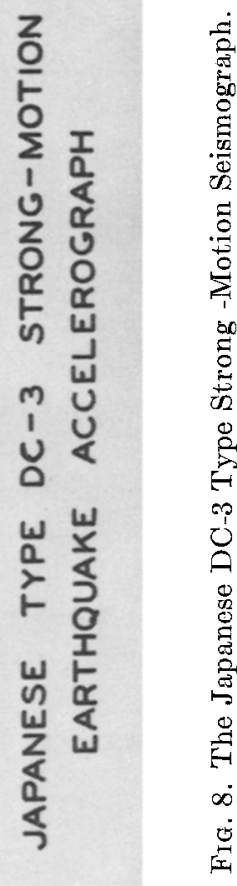


This new instrument, called the "U.S.C.G.S. Seismoscope", is shown in the photograph of figure 9 . The base of the instrument is about 10 inches square, and it is protected in use by the stainless steel cover shown at the left.

The Seismoscope consists of a free conical pendulum which can move in any horizontal direction. The wire flexure pivot support of the pendulum moves with the ground, and the resulting angular deflections relative to the instrument frame are recorded by a scriber on a smoked spherical watch glass. A typical record obtained during a test of the instrument is shown in figure 10. Eddy current damping of the pendulum is provided by an aluminum disk in the form of a segment of a spherical shell, which moves between the poles of a permanent magnet system. Since the motion in a horizontal plane is traced out as a permanent record, the sequence of events can be followed even though no time-recording is employed. In this way much more information than would be obtained from an indication of maximum displacements alone can be secured by a very simple means.

Complete drawings of the instrument, as well as details of design, construction, and test are included in two special reports ${ }^{12,13}$.

The Seismoscope records the response of a single-degree-of-freedom system of prescribed period and damping to the earthquake ground motion. It thus gives directly one point on the response spectrum curve of figure 2. The design parameters for the Seismoscope were selected to give the single response spectrum point which would be most descriptive of typical strong earthquakes. After a study of the response spectrum curves for all of the recorded strong-motion earthquakes, it was decided that the single spectrum point that would give the maximum information would be a period of about 0.75 seconds and $10 \%$ of critical damping. The suitability of this particular spectrum point was further verified by studies of the unusually complete strong-motion accelerograph data from the San Francisco earthquake of March 22, $1957^{14}$. The dimensions of the instrument have been selected so that with a standard $2 \frac{1}{2} \mathrm{in}$. watch glass recording plate a full-scale deflection represents a maximum relative velocity response spectrum value of $S_{V} \approx$ $2 \mathrm{ft} / \mathrm{sec}$.

The damping of the instrument is not constant, but varies somewhat with the pendulum amplitude. A technique has been developed for adjusting and measuring the damping, and for correcting the results, which gives a satisfactory accuracy under field conditions ${ }^{15}$.

As an over-all check on the field accuracy of the Seismoscope, the instrument was mounted next to standard recording accelerographs at several locations. The earthquake of August 27, 1959 at Hebgen Dam, Montana, gave good simultaneous records from the Accelerograph and the Seismoscope ${ }^{11}$. In figure 11 are shown the velocity response spectrum curves as calculated from the acceleration-time record for this earthquake by the electric analog response spectrum analyzer. On the same curves are shown the single spectrum points as obtained from the seismoscope. It will be observed that an excellent agreement exists.

Similar checks have been obtained for several other earthquakes, and while it is not to be expected that the agreement will always be as close as indicated in figure 8 , these tests have shown that under typical conditions of field installation and adjustment, an accuracy of 5-10 per cent may be attained. This accuracy is believed to be sufficient for the intended application of the device. 


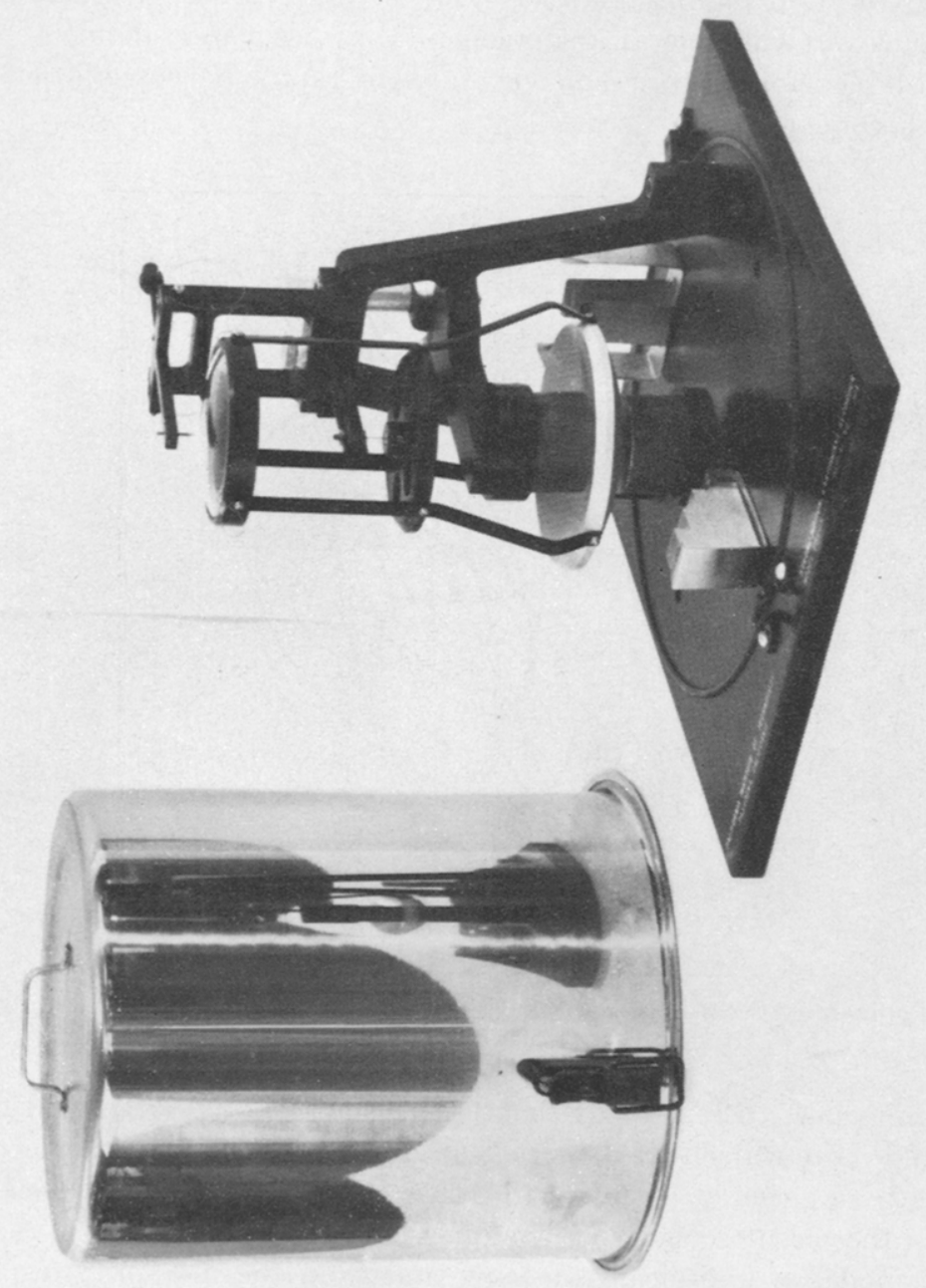


The proposed use of the Seismoscope is as a supplement to the Accelerograph. It is suggested that some $15-20$ Seismoscopes might be grouped in the vicinity of each Strong-Motion Accelerograph so that the effects of various local geology and soil conditions could be evaluated. It is realized that the limited data from the Seismoscope cannot replace the Accelerograph, but it is felt that the increased local coverage permitted by the relatively low cost and ease of installation and maintenance makes it valuable as a supplemental device. Since about 50 Seismoscopes can be obtained for the price of one Accelerograph, the possibilities of increased coverage become evident.

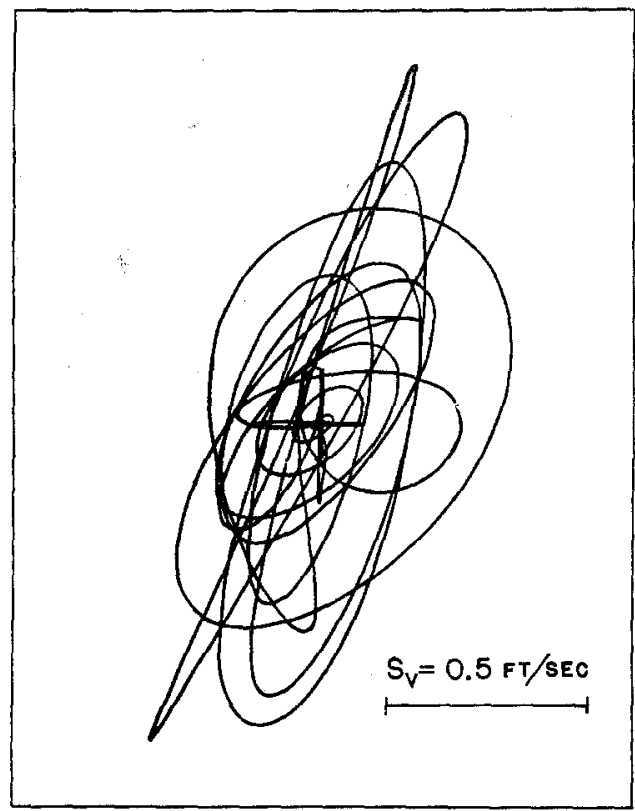

FIG. 10. Typical test record obtained on the U.S.C.G.S. Seismoscope. Damping $=10$ per cent of critical; period $=0.73$ second.

It is important to remember that the Seismoscope is not intended to measure the ground motion itself; it is neither an accelerometer nor a displacement meter, and no attempt should be made to derive acceleration or displacement information from the Seismoscope records alone. The Seismoscope can be thought of as a dynamic model of a typical structure, and from the measured responses of this typical structure during an earthquake, approximate calculations of the behavior of other structures subjected to the same earthquake can be made. Since it is structural response rather than ground motion which is of primary significance to the engineer, the Seismoscope can produce information of direct application to many problems of earthquake-resistant design.

For areas in which typical response spectrum curves are not available, there is of course the possibility that Seismoscopes could be installed in groups including elements of various periods and damping. This idea goes back to Dr. K. Suyehiro, who in 1926 produced a "Seismic Vibration Analyzer" embodying a very similar 

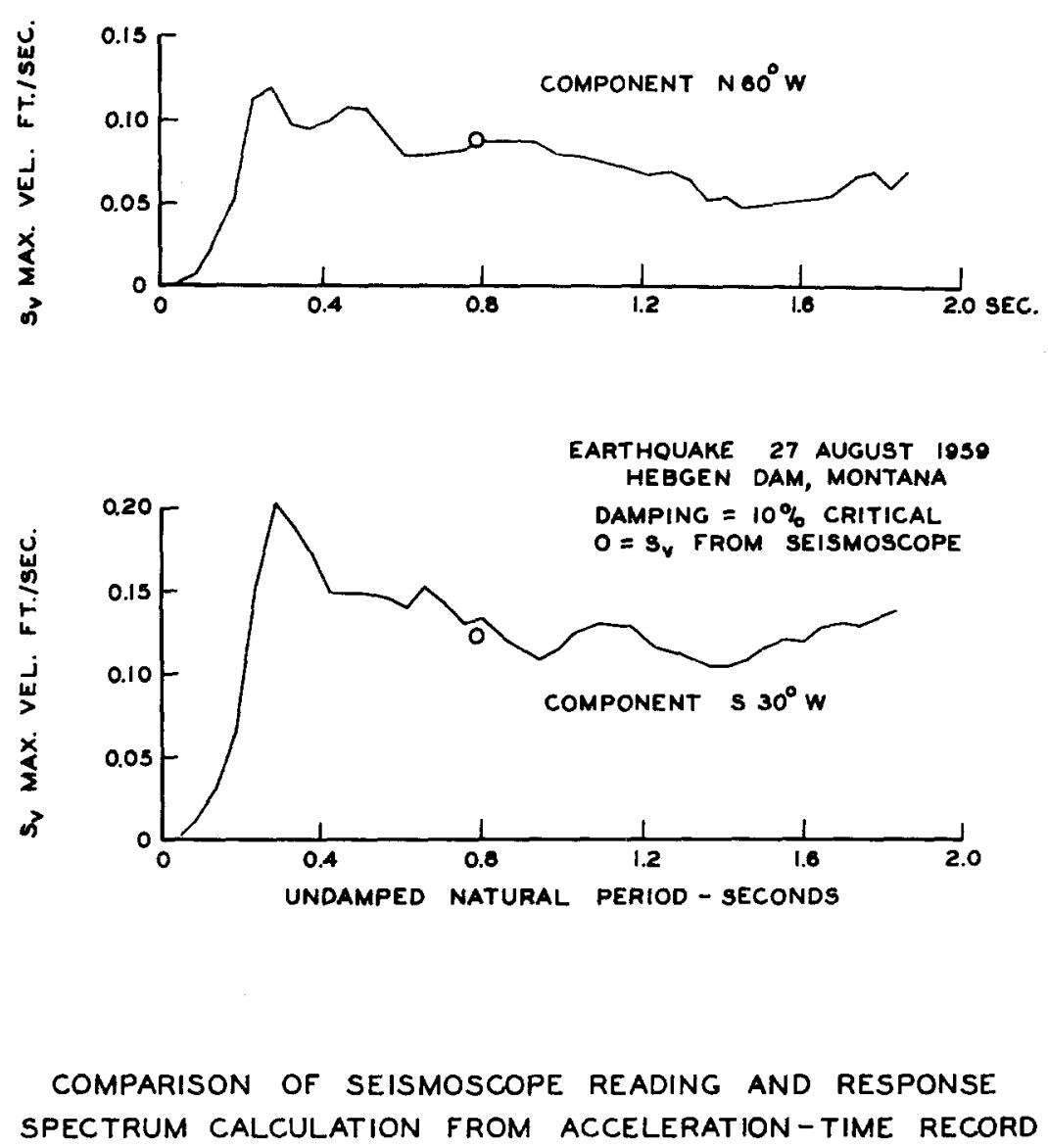

FIG. 11. Comparison of U.S.C.G.S. Seismoscope results with spectrum analysis of simultaneously recorded ground acceleration. 
principle $^{16,1}$. A modern adaptation of this principle has recently been developed in the U.S.S.R., and has been described by A. G. Nazarov"17, ${ }^{18}$. The Russian "AIS-2 Seismometer" consists of a series of spherical pendula of different periods marking on a smoked glass. A relatively small record is obtained, and is examined by a microscope. Elements for vertical motion are also provided in some of the models. The data from these instruments should be directly comparable with that from the U.S.C.G.S. Seismoscope if the complete dynamic properties of the Russian device were known. The U.S.C.G.S. Seismoscope is also similar to the instrument developed in the U.S.S.R. in 1953 by S. V. Medvedev, which has a period of 0.25 seconds and about $8 \%$ of critical damping. ${ }^{19,20}$

At present about 100 of the U.S.C.G.S. Seismoscopes have been installed in California, and an additional 30 are being installed. Instruments have been sent to a number of other countries to serve as models for the development and construction of similar devices. A group of 50 Seismoscopes is now being built at the Instituto Seismologico de Chile, and interesting data should be forthcoming from this area in the near future. It will be important that calibration studies and tests made on these Chilean Seismoscopes be in such a form that the results can be directly compared with data from the U.S.C.G.S. Seismoscopes now installed in the Western United States.

\section{ACKNOWLEDGMENTS}

Thanks are expressed to Mr. W. K. Cloud, Chief of the Seismological Field Survey of the United States Coast and Geodetic Survey for information on the U.S.C.G.S. Accelerograph and for the data on field tests of the U.S.C.G.S. Seismoseope. Drs. N. Nasu, R. Takahasi, and K. Kanai of the Earthquake Research Institute of the University of Tokyo, and Mr. M. Saito of Akashi Seisakusho Ltd., kindly supplied information on the Japanese strong-motion accelerographs and instrumentation program.

\section{REFERENCES}

1. Suyehiro, K., "Engineering Seismology-Notes on American Lectures", Proc. A.S.C.E., Vol, 58, No. 4, (1932).

2. Freeman, J. R., Earthquake Damage and Earthquake Insurance, MeGraw-Hill Book Company, Ine., New York and London (1932).

3. Takahasi, R., "The SMAC Strong Motion Accelerograph and Other Latest Instruments for Measuring Earthquakes and Building Vibrations", Proc. World Conference on Earthquake Engineering, Earthquake Engineering Research Institute and the University of California, Berkeley, (1956).

4. Strong-Motion Earthquake Observation Committee, Strong-Motion Earthquake Records in Japan, Vol. 1, Earthquake Research Institute, University of Tokyo, March 1960.

5. Neumann, F., United States Earthquakes, 1940, U.S. Department of Commerce, Coast and Geodetic Survey, Serial No. 647, Washington, D.C., (1942).

6. Housner, G. W., R. R. Martel and J. L. Alford, "Spectrum Analysis of Strong-Motion Earthquakes", Bull. Seis. Soc. Amer., Vol. 43, No. 2, (April 1953).

7. Heek, N. H., H. E. MeComb and F. P. Ulrich, "Strong-Motion Program and Tiltmeters", Earthquake Investigations in California, Spec. Pub. No. 201, U.S. Department of Commerce, Coast and Geodetic Survey, Washington, D.C., (1936).

8. Hudson, D. E. "Ground Motion Measurements in Earthquake Engineering", Proc. Sympos. on Earthq. Eng., University of Roorkee, Roorkee, India, 1959.

9. Cloud, W. K., "Intensity Distribution and Strong-Motion Seismograph Results", Nevada Earthquakes of December 16, 1954", Bull. Seis. Soc. Amer., Vol. 47, No. 4, (Oct. 1957). 
10. Hudson, D. E., "A Comparison of Theoretical and Experimental Determinations of Building Response to Earthquakes", Proc. Second World Conference on Earthquake Engineering, Tokyo and Kyoto, Japan, (1960).

11. Cloud, W. K., and D. E. Hudson, "A Simplified Instrument for Recording Strong Motion Earthquakes", Bull. Seis. Soc. Amer., Vol. 51, No. 2, (April 1961).

12. Hudson, D. E., The Wilmot Survey Type Strong-Motion Earthquake Recorder, Earthquake Engineering Research Laboratory, California Institute of Technology, (September 1958).

13. Hudson, D. E. and W. D. Iwan, The Wilmot Survey Type Strong-Motion Earthquake Recorder (The U.S.C.G.S. Seismoscope) Part II, Earthquake Engineering Research Laboratory, California Institute of Technology, (November 1960).

14. Hudson, D. E. and G. W. Housner, "An Analysis of Strong-Motion Accelerometer Data from the San Francisco Earthquake of March 22, 1957", Bull. Seis. Soc. Amer., Vol. 48, No. 3, (July 1958).

15. Maley, R. P., Standard Procedure for Adjustment and Installation of U.S. Coast and Geodetic Survey Seismoscopes, Report to Seismological Field Survey, U.S. Coast and Geodetic Survey, 1960.

16. Suyehiro, K., "A Seismic Vibration Analyzer and the Records Obtained Therewith", Bull. Earthquake Res. Inst., Tokyo, Vol. 1, (1926).

17. Nazarov, A. G., The Method of Engineering Analysis of Seismic Forces, Aeademy of Sciences of the Armenian S.S.R., Yerevan, 1959 (in Russian).

18. Nazarov, A. G., B. K. Karapetian and S. A. Shahinian, "The Method of Direct Determination of Reduced Spectra of Seismic Accelerations", Proc. Second World Conference on Earthquake Engineering, Tokyo and Kyoto, Japan, 1960 (in English).

19. Savarensky, E. F., and Kirnos, D. P., Elements of Seismology and Seismometry, Moscow, 1955 (English Translation)

20. Medvedev, S. V., Engineering Seismology, State Publishing House for Construction, Architecture, and Construction Materials, Moscow, 1962. (In Russian).

California Institute of Technology

Pasadena, California.

Manuscript received April 12, 1962. 